\title{
Goal-directed fluid therapy for microvascular free flap reconstruction following mastectomy: A pilot study
}

\author{
Duane Funk MD FRCPC, James Bohn MD, WAC Mutch MD FRCPC, Tom Hayakawa MD FRCSC, Edward W Buchel MD
}

D Funk, J Bohn, WAC Mutch, T Hayakawa, E Buchel. Goal-directed fluid therapy for microvascular free flap reconstruction following mastectomy: A pilot study. Plast Surg 2015;23(4):231-234.

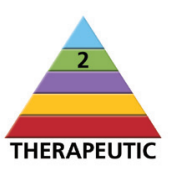

BACKGROUND: Fluid management of the surgical patient has undergone a paradigm shift over the past decade. A change from 'wet' to 'dry' to a 'goal-directed' approach has been witnessed. The fluid management of patients undergoing free flap reconstruction is particularly challenging. This is typically a long operation with minimal surgical stimulation, and hypotension often ensues. The use of vasopressors in these cases is contraindicated to maintain adequate flow to the flap. Hypotension is often treated with intravenous fluid boluses. However, aggressive fluid administration to maintain adequate blood pressure can result in flap edema, venous engorgement and, ultimately, flap loss.

OBJECTIVE: The primary objective of the present study was to determine whether goal-directed fluid therapy, titrated to maintain stroke volume variation $\leq 13 \%$, with the use of an arterial pulse contour device results in improved postoperative cardiac index (CI) and stroke volume index (SVI) with reduced amounts of intravenous fluid. The primary end points studied were CI, SVI and cumulative crystalloid/colloid administration. METHODS: Twenty female patients undergoing simultaneous microvascular free flap reconstruction immediately following mastectomy were studied. Preoperative and intraoperative care were standardized. Each patient received intra-arterial blood pressure monitoring. In all patients, cardiac output measurement occurred throughout the intraoperative period using the arterial pulse contour device. Control patients had their fluid administered at the discretion of the anesthesiologist (blinded to results from the cardiac output device). Patients in the intervention group had a baseline crystalloid infusion of $5 \mathrm{~mL} / \mathrm{kg} / \mathrm{h}$, with intravenous colloid boluses to maintain a stroke volume variation $\leq 13 \%$.

RESULTS: There was no difference in heart rate or mean arterial pressure between groups at the end of the operation. However, at the end of the operation, the intervention group had significantly higher mean $( \pm \mathrm{SD}) \mathrm{CI}$ $\left(3.8 \pm 0.8 \mathrm{~L} / \mathrm{min} / \mathrm{m}^{2}\right.$ versus $\left.3.0 \pm 0.5 \mathrm{~L} / \mathrm{min} / \mathrm{m}^{2} ; \quad \mathrm{P}=0.02\right)$ and SVI $\left(51.4 \pm 2.4 \mathrm{~mL} / \mathrm{m}^{2}\right.$ versus $\left.43.3 \pm 2.3 \mathrm{~mL} / \mathrm{m}^{2} ; \mathrm{P}=0.03\right)$. This improved $\mathrm{CI}$ and SVI was achieved with similar amounts of administered intraoperative fluid $(5.8 \pm 0.5 \mathrm{~mL} / \mathrm{kg} / \mathrm{h}$ versus $5.0 \pm 0.7 \mathrm{~mL} / \mathrm{kg} / \mathrm{h}$, control versus intervention). The intervention group required less postoperative fluid resuscitation during the early postoperative period (total fluid administered from end of operation to midnight of the operative day, $6.4 \pm 1.9 \mathrm{~mL} / \mathrm{kg} / \mathrm{h}$ versus $10.2 \pm 3.3 \mathrm{~mL} / \mathrm{kg} / \mathrm{h}$, intervention versus control, respectively, $\mathrm{P}<0.01$ ).

DISCUSSION: Goal-directed fluid therapy using minimally invasive cardiac output monitoring resulted in improved end-operative hemodynamics, with less 'rescue' fluid administration during the perioperative period.

Key Words: Goal-directed fluid therapy; Intravenous fluid; Mastectomy; Microvascular free flap reconstruction

Since the 1940s, the prevailing wisdom regarding the amount of fluid to administer to surgical patients has undergone several paradigm shifts $(1-4)$.

The fluid management of patients undergoing microvascular free flap reconstruction is particularly challenging. This is typically a long operation with minimal surgical stimulation. The use of vasopressors in these cases is contraindicated so as not to compromise blood flow to the flap.

\author{
Une perfusion de liquides axée sur des objectifs pour la \\ reconstruction par lambeau libre microvasculaire après \\ une mastectomie : un projet pilote
}

HISTORIQUE : La prise en charge des liquides du patient opéré a connu un changement de paradigme depuis dix ans. On a constaté un passage de « mouillé » à « sec ", puis à une démarche " axée sur des objectifs ». La prise en charge des liquides des patients qui subissent une reconstruction par lambeau libre est particulièrement difficile. C'est habituellement une longue opération associée à une stimulation chirurgicale minimale, qui entraîne souvent une hypotension. Le recours aux vasopresseurs est contre-indiqué dans ces situations, pour maintenir un débit suffisant dans le lambeau. L'hypotension est souvent traitée au moyen de bolus de liquide intraveineux. Cependant, l'administration énergique de liquides pour maintenir une tension artérielle suffisante peut provoquer un œdème du lambeau, un engorgement veineux et, au bout du compte, la perte du lambeau.

OBJECTIF : L'objectif primaire de la présente étude visait à déterminer si la perfusion de liquides axée sur des objectifs, titrée pour maintenir la variation du volume de débit systolique à un maximum de $13 \%$ au moyen d'un dispositif de contour de l'onde de pouls artériel, assure une amélioration de l'indice cardiaque postopératoire (IC) et de l'indice de débit systolique (IDS) et une moins grande utilisation de liquide intraveineux. Les paramètres primaires étudiés étaient l'IC, l'IDS et l'administration cumulative de crystalloïdes et de colloïdes.

MÉTHODOLOGIE : Les chercheurs ont étudié 20 patientes subissant une reconstruction simultanée par lambeau libre microvasculaire suivant immédiatement une mastectomie. Les soins préopératoires et peropératoires ont été standardisés. Chaque patiente était soumise à une surveillance de la tension intra-artérielle. Le débit cardiaque de toutes les patientes a été mesuré pendant la période peropératoire au moyen du dispositif de contour de l'onde de pouls artériel. Les patientes témoins se sont fait administrer le liquide au moment déterminé par l'anesthésiste (non informé de résultats du dispositif de débit cardiaque). Les patientes du groupe d'intervention ont reçu une infusion crystalloïde initiale de $5 \mathrm{~mL} / \mathrm{kg} / \mathrm{h}$, de même que des bolus de colloïde intraveineux pour maintenir une variation du débit systolique à un maximum de $13 \%$.

RÉSULTATS : Il n'y avait pas de différence de fréquence cardiaque ou de tension artérielle moyenne entre les groupes à la fin de l'opération. Cependant, le groupe d'intervention présentait alors un IC moyen ( \pm ÉT, 3,8 $\pm 0,8 \mathrm{~L} / \mathrm{min} / \mathrm{m}^{2}$ par rapport à $\left.3,0 \pm 0,5 \mathrm{~L} / \mathrm{min} / \mathrm{m}^{2} ; \mathrm{P}=0,02\right)$ et un IDS $\left(51,4 \pm 2,4 \mathrm{~mL} / \mathrm{m}^{2}\right.$ par rapport à $43,3 \pm 2,3 \mathrm{~mL} / \mathrm{m}^{2} ; \mathrm{P}=0,03$ ) considérablement plus élevés. Cette amélioration de l'IC et de l'IDS se produisait au moyen de quantités similaires de liquide peropératoire $(5,8 \pm 0,5 \mathrm{~mL} / \mathrm{kg} / \mathrm{h}$ par rapport à $5,0 \pm 0,7 \mathrm{~mL} / \mathrm{kg} / \mathrm{h}$, groupe témoin par rapport au groupe d'intervention). Le groupe d'intervention avait besoin de moins de réanimation par liquide postopératoire au début de la période postopératoire (quantité totale de liquide administrée entre la fin de l'opération et minuit le jour de l'opération, $6,4 \pm 1,9 \mathrm{~mL} / \mathrm{kg} / \mathrm{h}$ par rapport à $10,2 \pm 3,3 \mathrm{~mL} / \mathrm{kg} / \mathrm{h}$, groupe d'intervention par rapport au groupe témoin, respectivement, $\mathrm{P}<0,01$ ).

EXPOSÉ : La perfusion de liquides axée sur des objectifs faisant appel à une surveillance minimalement invasive du débit cardiaque assurait une amélioration de l'hémodynamique en fin d'opération, et l'administration d'un moins grand volume de liquide de « rattrapage » pendant la période périopératoire.

Inadequate volume replacement in these patients can potentially lead to poor flow in the flap with resultant ischemia and flap loss. Aggressive fluid administration in these patients, to maintain adequate blood pressure, can result in flap edema, venous engorgement and, ultimately, flap loss. There have been several retrospective studies that have examined fluid administration in these patients and found that excessive perioperative fluid administration has been associated with flap loss $(5,6)$.

${ }^{1}$ University of Manitoba; ${ }^{2}$ Department of Anesthesia and Perioperative Medicine, University of Manitoba, Winnipeg, Manitoba

Correspondence: Dr Duane Funk, University of Manitoba, Department of Anesthesia and Perioperative Medicine, 2nd Floor, Harry Medovy

House, 671 William Avenue, Winnipeg, Manitoba R3T 2N2. Telephone 204-787-2261, fax 204-787-4291, e-mail funk@cc.umanitoba.ca 


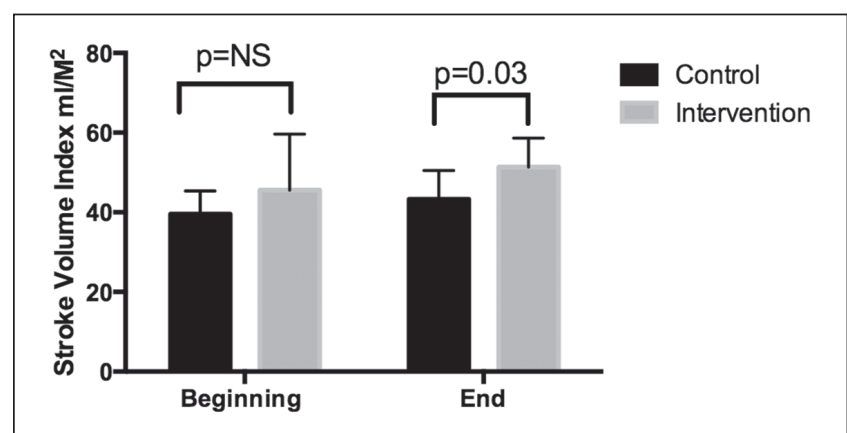

Figure 1) Comparison of stroke volume index (SVI) measurements $\left(\mathrm{mL} / \mathrm{m}^{2}\right)$ between control and intervention groups at the beginning and end of surgery. Values are mean \pm SD. The SVI was higher in the intervention versus the control group at the end of surgery $\left(51.4 \pm 2.4 \mathrm{~mL} / \mathrm{m}^{2}\right.$ versus $43.3 \pm 2.3 \mathrm{~mL} / \mathrm{m}^{2}$, $P=0.03)$. NS Not significant

Tailoring fluid management for these patients, by using a goaldirected approach, may be the most beneficial. In this context, administering fluids based on need as determined by an upper limit of stroke volume variation (SVV) is an approach with potential merit. SVV is the natural variation in stroke volume (SV) that occurs while a patient is undergoing controlled mechanical ventilation. SV and arterial blood pressure rise during mechanical inspiration as pressure in the thorax literally squeezes blood from the pulmonary veins into the left ventricle (Figure 1). The subsequent heartbeats have a lower SV due to the pulmonary circuit being relatively emptied of blood. When SVV exceeds $13 \%$, patients are believed to be volume responsive (ie, giving a fluid bolus when SVV is $>13 \%$ will likely result in an increase in that patients cardiac output [CO]).

In this regard, in the present pilot trial, we hypothesized that administering intravenous fluid when SVV was $>13 \%$ in patients undergoing simultaneous mastectomy and microvascular free flap reconstruction would result in improved cardiac index (CI) and lower intraoperative fluid administration compared with standard of care. The value of SVV of $13 \%$ was chosen because it has been described in previous studies as indicating that a patient is volume responsive (7) (ie, when the SVV is $>13 \%$, the administration of fluid has a high probability of increasing the patient's $\mathrm{CO}$ ).

\section{METHODS}

After approval by the University of Manitoba Biomedical Research Ethics Board (Winnipeg, Manitoba), 20 women undergoing simultaneous mastectomy and microvascular free flap reconstruction were approached before surgery to enter the present study. Informed, written, witnessed consent was obtained from all participants. The present trial was registered at ClinicalTrials.gov, with the trial identification number NCT00869297.

Patients were randomly assigned before surgery into intervention and control groups with the use of cards drawn from a sealed envelope.

The surgical and anesthetic techniques were at the discretion of the attending surgeon and anesthesiologist. An arterial catheter was placed before the induction of general anesthesia and this was connected inline to a sensor (FloTrac, Edwards Life Sciences, USA) to measure $\mathrm{CO}, \mathrm{CI}, \mathrm{SV}$, stroke volume index (SVI, stroke volume indexed for body surface area) and SVV. These parameters were displayed on a Vigileo monitoring device (Edwards Life Sciences, USA) and simultaneously on a monitor (Intellivue 70, Phillips, USA).

Patients were ventilated in volume control mode with tidal volume of $8 \mathrm{~mL} / \mathrm{kg}$ based on ideal body weight (ideal body weight $=5.5+0.91$ [height in $\mathrm{cm}-152.4]$ ). Respiratory rate was adjusted to achieve an end tidal carbon dioxide level of $35 \mathrm{mmHg}$ to $40 \mathrm{mmHg}$. Positive endexpiratory pressure was set at $5 \mathrm{cmH}_{2} \mathrm{O}$. Fraction of inspired oxygen was titrated to maintain an oxygen saturation $>95 \%$. The attending anesthesiologist was allowed to change the respiratory rate to achieve normal carbon dioxide tension during the surgery.
TABLE 1

Patient demographics

\begin{tabular}{lcc}
\hline & Control & Intervention \\
\hline $\begin{array}{l}\text { Age, years, median } \\
\text { (interquartile range) }\end{array}$ & $51(42-64)$ & $47(29-64)$ \\
Weight, kg & $70.0 \pm 12$ & $82.4 \pm 17$ \\
Height, $\mathrm{cm}$ & $159 \pm 7$ & $167 \pm 5$ \\
Body mass index, kg/m & $27.6 \pm 4.7$ & $29.4 \pm 5.7$ \\
Medical comorbidities, $\mathrm{n}$ & Asthma, 2; & Asthma, 3; \\
& hyperthyroidism, 1 & hypertension, 3; \\
& & hypercholesterolemia, 1 \\
\hline
\end{tabular}

Data presented as mean $\pm S D$ unless otherwise specified

The microvascular free flap reconstruction was performed immediately after the mastectomy during the same anesthetic per usual protocol.

In the intervention group, the intraoperative fluid management was dictated by measurements obtained from the FloTrac sensor and Vigileo monitor. The patients in the intervention group received lactated Ringer's solution infusing at a rate of $5 \mathrm{~mL} / \mathrm{kg} / \mathrm{h}$ ideal body weight for the duration of surgery. This infusion rate was chosen based on the study by Gan et al (8). Intravenous colloid in the form of Voluven (Fresenius Kabi, Germany) was the chosen colloid administered during the study. Voluven boluses of $250 \mathrm{~mL}$ were administered when the SVV was $>13 \%$, a percentage value that has been used in other studies to indicate that a patient is volume responsive (9). If the mean arterial pressure (MAP) was $<60 \mathrm{mmHg}$ and SVV was $\leq 13 \%$, and CI was $>2.2 \mathrm{~L} / \mathrm{min} / \mathrm{m}^{2}, 5 \mathrm{mg}$ boluses of ephedrine were administered to maintain MAP $>60 \mathrm{mmHg}$.

In the control group, the anesthesia care provider was blinded to the hemodynamic data generated by the FloTrac (CO, CI, SV and SVV) by means of an opaque index card that covered the anesthetic monitor. The intraoperative fluid management, with respect to volume, rate and balance between crystalloid and colloid in this group was at the discretion of the attending anesthesiologist. No background fluid administration was prescribed for this group in accordance with the standard of care for these patients at the authors' institution, where fluid administration is entirely at the discretion of the attending anesthesiologist.

Intraoperative hemodynamic data were collected at $60 \mathrm{~Hz}$ by TrendFace Solo software (iExcellence, Germany). The per-second values were meaned to obtain data for each minute of surgery; this was performed off-line using Excel (Microsoft Corporation, USA) Intraoperative data collected included operative duration, fluid administration (crystalloid, colloid, blood products) and fluid losses (blood and urine output). Fluid balance monitoring was continued until the second postoperative day or until discharge, if this occurred before postoperative day 2 .

\section{Statistical analysis}

Because the present analysis was a pilot study, a power analysis was not undertaken because changes, if any, that may have occurred in the intervention group compared with the standard management group with respect to fluid administration or $\mathrm{CO}$ were unknown. Data are presented as mean \pm SD when normally distributed. Data were analyzed using the Student's $t$ test. Between-group comparisons were deemed significantly different at $\mathrm{P}<0.05$. Statistical analysis was performed using Graph Pad Prism (GraphPad, USA).

\section{RESULTS}

A total of 20 patients were randomly assigned in the study, 10 in each group. Mean duration of surgery was $436 \pm 115 \mathrm{~min}$. Operative duration did not differ significantly between the control $(413 \pm 113 \mathrm{~min})$ and the intervention groups $(463 \pm 118 \mathrm{~min})$. Demographic information for the two groups are summarized in Table 1.

At the beginning of the surgery, heart rate (HR) was higher in the control group than in the intervention $(68 \pm 7$ beats/min versus 


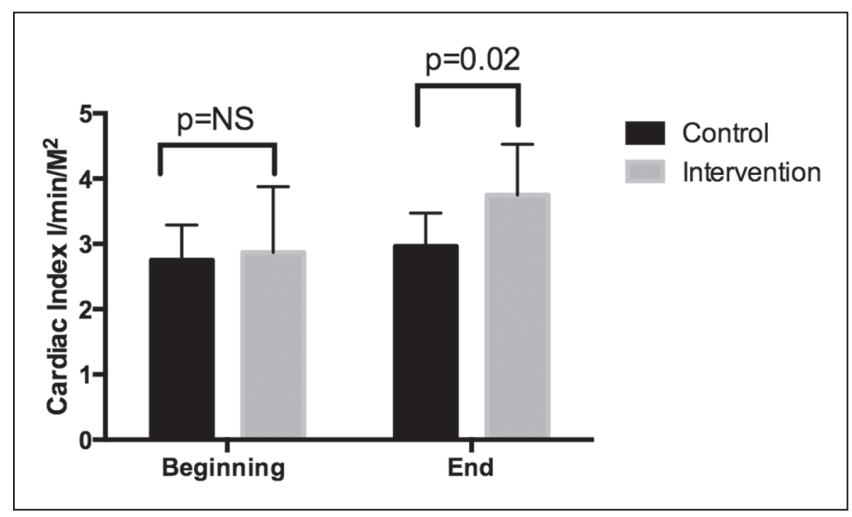

Figure 2) Comparison of cardiac index measurements $\left(\mathrm{L} / \mathrm{min} / \mathrm{m}^{2}\right)$ between control and intervention groups at the beginning and end of surgery. Values are presented as mean $\pm S D$. Cardiac index was significantly higher in the intervention group at the end of the surgery $\left(3.8 \pm 0.8 \mathrm{~L} / \mathrm{min} / \mathrm{m}^{2}\right.$ versus $\left.3.0 \pm 0.5 \mathrm{~L} / \mathrm{min} / \mathrm{m}^{2} ; P=0.02\right)$. NS Not significant

$55 \pm 9$ beats $/ \mathrm{min}, \mathrm{P}<0.05)$. MAP was also higher at the beginning of the surgery in the control versus the intervention group $(78 \pm 10 \mathrm{mmHg}$ versus $68 \pm 11 \mathrm{mmHg}, \mathrm{P}=0.03$ ). At the end of the surgery, MAP and HR were not significantly different between groups. Cardiac index $\left(3.8 \pm 0.8 \mathrm{~L} / \mathrm{min} / \mathrm{m}^{2}\right.$ versus $3.0 \pm 0.5 \mathrm{~L} / \mathrm{min} / \mathrm{m}^{2}$, intervention versus control; $\mathrm{P}=0.02)$, and stroke volume index $\left(51.4 \pm 2.4 \mathrm{~mL} / \mathrm{m}^{2}\right.$ versus $43.3 \pm 2.3 \mathrm{~mL} / \mathrm{m}^{2}$, intervention versus control; $\mathrm{P}=0.03$ ) were significantly higher in the intervention group versus the control group at the end of the surgery (Figures 2 and 3 ).

As mentioned above, due to the varying duration of each individual surgery, fluid administration was normalized and analyzed on a $\mathrm{mL} / \mathrm{kg} / \mathrm{h}$ basis. Total intraoperative fluid administration (crystalloid and colloid) was similar in the control versus the intervention group $(5.8 \pm 0.5 \mathrm{~mL} / \mathrm{kg} / \mathrm{h}$ versus $5.0 \pm 0.7 \mathrm{~mL} / \mathrm{kg} / \mathrm{h}, \mathrm{P}=$ not significant $)$. The amount of fluid administered from the time the patients reached the recovery room to midnight of the operative day (postoperative day 0 ) was significantly higher in the control group $(10.2 \pm 3.3 \mathrm{~mL} / \mathrm{kg} / \mathrm{h}$ versus $6.4 \pm 1.9 \mathrm{~mL} / \mathrm{kg} / \mathrm{h}, \mathrm{P}<0.01)$. Fluid administration in the postoperative period was at the discretion of the surgical house staff. The usual trigger for postoperative fluid administration in these patients is hypotension (systolic blood pressure $<90 \mathrm{mmHg}$, poor Doppler flap signal or urine output $<30 \mathrm{~mL} / \mathrm{h}$ for two consecutive hours).

The amount of fluid administered to patients during postoperative day 1 was similar between groups. There was no difference in blood loss, urine output or overall fluid balance between groups at the end of the study period (Table 2).

All of the fluid boluses in the intervention group occurred within the initial $40 \%$ of the case duration; $42 \%$ of the boluses were given during the first one-quarter of the case duration.

In the control group, there were a total of 21 instances where the SVV was $>13 \%$. A fluid bolus was given only three times when the SVV was $>13 \%$ (three of 21 , or $14 \%$ of occurrences). There were nine other times when patients received a bolus of fluid and the SVV was $\leq 13 \%$. The reasons for fluid bolus in these instances were low urine output (three of nine occasions) and decreased MAP (six of nine occasions). In these situations where a fluid bolus was administered when the SVV was $\leq 13 \%$, the CI was always $>2.2 \mathrm{~L} / \mathrm{min} / \mathrm{m}^{2}$, indicating adequate total body blood flow.

There were no significant postoperative complications (bleeding, flap failure, deep venous thrombosis, pulmonary embolus, reoperation or congestive heart failure) in either group. Length of stay also did not differ between groups.

\section{DISCUSSION}

In the present pilot study, we show that in patients undergoing simultaneous mastectomy and free flap reconstruction, fluid administration

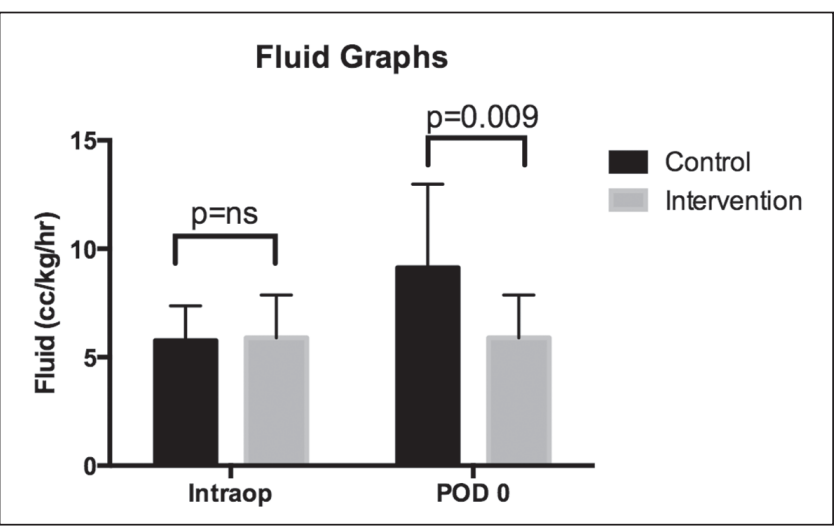

Figure 3) Fluid administration between control and intervention groups. Patients in the control group received more intraoperative (intraop) fluid $(5.8 \pm 0.5 \mathrm{~mL} / \mathrm{kg} / \mathrm{h}$ versus $5.0 \pm 0.7 \mathrm{~mL} / \mathrm{kg} / \mathrm{h} ; P=0.40)$, and more rescue fluid $(10.2 \pm 3.3 \mathrm{~mL} / \mathrm{kg} / \mathrm{h}$ versus $6.4 \pm 1.9 \mathrm{~mL} / \mathrm{kg} / \mathrm{h} ; P=0.009)$. $P$ values based on Student's t test. ns Not significant; POD Postoperative day

\section{TABLE 2}

\section{Fluid administration data}

\begin{tabular}{lccc}
\hline & Control & Intervention & $\mathbf{P}$ \\
\hline Intraoperative, $\mathrm{mL} / \mathrm{kg} / \mathrm{h}$ & & & \\
$\quad$ Total fluid & $5.8 \pm 0.5$ & $5.0 \pm 0.7$ & 0.40 \\
$\quad$ Crystalloid & $5.5 \pm 2.8$ & $3.6 \pm 0.8$ & 0.08 \\
$\quad$ Colloid & $1.1 \pm 0.7$ & $0.7 \pm 0.5$ & 0.23 \\
Postoperative day 0, $\mathrm{mL} / \mathrm{kg} / \mathrm{h}$ & & & \\
$\quad$ Total fluid & $10.2 \pm 3.3$ & $6.4 \pm 1.9$ & $<0.01$ \\
$\quad$ Crystalloid & $9.1 \pm 3.5$ & $5.3 \pm 1.7$ & $<0.01$ \\
$\quad$ Colloid & $1.4 \pm 0.5$ & $0.6 \pm 0.5$ & $<0.01$ \\
Total blood loss, $\mathrm{mL} / \mathrm{kg}$ & $16 \pm 6$ & $12 \pm 4$ & 0.1 \\
Total fluid, $\mathrm{mL} / \mathrm{kg}$ & $164 \pm 58$ & $128 \pm 40$ & 0.2 \\
\hline
\end{tabular}

Data presented as mean $\pm S D$. Total blood loss, total crystalloid, total colloid and total fluid are represented as $\mathrm{mL} / \mathrm{kg}$ and are for the duration of the patients' hospital stay. Postoperative day 0 refers to the time the patients were admitted to the recovery room to midnight of the operative day

based on a target value of SVV $>13 \%$ resulted in improved CI and SVI at the end of the procedure. The higher CI and SVI at the end of the surgery occurred despite similar HR and MAP measurements. Our study confirms the finding of numerous other studies that have demonstrated the inaccuracy of traditional hemodynamic parameters (such as blood pressure and HR) in assessing organ flow.

Organs require both pressure and flow for optimal function. Pressure measurements are routine and simple in the operating room or the intensive care unit, and this explains why clinicians have relied on them so heavily. Measuring blood flow has, until recently, only been possible with the use of a pulmonary artery catheter or with the use of echocardiographic techniques.

Recently, there has been a marked increase in the number and type of devices that can measure $\mathrm{CO}$ with minimally invasive approaches (10). When these monitors are used in a goal-directed fashion (ie, titrating fluid to either a maximal SV or CO) they have consistently demonstrated an improvement in outcome (particularly length of stay and decreased complications) in patients undergoing high-risk surgery (11-16). Virtually all of these goal-directed studies have utilized a flow-directed monitor to maximize CO and SV with the use of colloid boluses.

The fluid management of patients undergoing free flap reconstruction is challenging. Because these cases have little surgical stimulation and the use of vasopressors is relatively contraindicated, clinicians often treat hypotension with fluid boluses. The administration of excessive amounts of fluid to these patients can lead to adverse outcomes due to 
the development of interstitial edema that causes venous engorgement and reduced flap blood flow.

Clark et al (5) found that crystalloid volume $>130 \mathrm{~mL} / \mathrm{kg}$ for the first $24 \mathrm{~h}$ after surgery in head and neck surgery resulted in a threefold increase in complications. Fluid administration was also an independent predictor of medical complications in this study. Myers et al (6) also found that greater fluid administration in head and neck surgery resulted in more complications. This study did not look at fluid on a $\mathrm{mL} / \mathrm{kg}$ or a $\mathrm{mL} / \mathrm{kg} / \mathrm{h}$ basis, making conclusions about the actual volume administered to their patients challenging to interpret.

To our knowledge, the issue of fluid administration in patients undergoing free flap for mastectomy has never been examined. In keeping with the above-mentioned data, our institutional practice is to utilize a restricted fluid strategy, one that has been shown in the literature to be beneficial to patients (1).

Using a so-called 'dry' strategy is not without its drawbacks, however, as demonstrated by the significantly lower CO and SV at the end of the study in our control group. This suggests that these patients were under-resuscitated when compared with the intervention group. Further evidence of this under-resuscitation is demonstrated by the significantly larger fluid administration in the recovery room and on the surgical ward until midnight of the operative day $(10.2 \pm 3.3 \mathrm{~mL} / \mathrm{kg} / \mathrm{h}$ versus $6.4 \pm 1.9 \mathrm{~mL} / \mathrm{kg} / \mathrm{h}, \mathrm{P}<0.01)$. This extra fluid was in the form of boluses (because maintenance fluid therapy in these patients is standardized by the surgeons). Triggers for this extra fluid were decreased blood pressure or urine output, or clinical evidence of poor perfusion of the flap (either by Doppler signalling or clinical judgment).

In the majority of the goal-directed therapy work to date, there has been greater fluid administered to patients in the intervention group. In contradistinction, in our study, there was a greater volume of fluid given to patients in the control group.

The only other study that failed to demonstrate a greater volume of fluid administered to the intervention group in a goal-directed approach was that of Noblett et al (12). They demonstrated fewer complications and decreased length of stay with similar amounts of intraoperative fluid administration. It is possible that in our study, as in the study by Noblett et al (12), it is not the amount of fluid administered but rather the timing of the administration that results in the improved perfusion at completion of surgery. In our study, the majority of the fluid boli occurred during the initial $40 \%$ duration of the surgery. Forty-two percent of the boli were given within the first one-quarter of the operative time course. This was similar to the Noblett et al (12) study, in which almost one-half of the fluid boli administered to maximize stroke volume were given during the first one-quarter of the surgery duration.

Our data from our control group also suggest that anesthesiologists often fail to give fluid when a patient is fluid responsive. In only three of 21 instances in the control group when the SVV was $>13 \%$ did the treating anesthetist deliver a fluid bolus.

Unexplained is why the control group received more fluid. It is possible that during the surgery, traditional hemodynamic parameters (HR, MAP, urine output) were altered enough to trigger extra fluid administration by the anesthesiologist. Despite this extra fluid, CO and SV were still higher in the intervention group, lending credence to our hypothesis that timing of fluid administration may be more important than the actual type or volume replaced.

There were several limitations to our study. First, it was a pilot trial and, as such, was limited in the number of patients enrolled. The difference in fluid administration between groups (favouring less in the intervention group) is also at issue. As mentioned above, the timing of fluid administration may be key. As a result, the present study poses several questions that need to be answered with a larger trial. Additionally, it is unclear whether this improvement in flow and decrease in 'rescue' fluid administration is beneficial to the patient.
However, it is plausible that a more titrated fluid approach that results in improved $\mathrm{CO}$ and avoids postoperative 'catch-up' could result in better function of the flap. However, due to the low complication rates in this type of surgery, we were not able to demonstrate any difference in patient outcome in the present study.

In conclusion, goal-directed fluid therapy that uses an elevated SVV as a trigger for fluid boluses, resulted in better CO and SV, and less 'rescue' fluid administration in patients undergoing simultaneous mastectomy and microvascular free flap reconstruction.

DISCLOSURES: The authors had no financial interest in any of the devices used during this pilot study project.

ACKNOWLEDGEMENTS: This project was funded from an operating grant from the University of Manitoba, Department of Anesthesia. The authors thank Linda Girling for technical help and data acquisition.

\section{REFERENCES}

1. Brandstrup B, Tonnesen H, Beier-Holgersen R, et al. Effects of intravenous fluid restriction on postoperative complications: Comparison of two perioperative fluid regimens: A randomized assessor-blinded multicenter trial. Ann Surg 2003;238:641-8.

2. Coller FA, Campbell KN, Vaughan HH, Iob LV, Moyer CA. Postoperative salt intolerance. Ann Surg 1944;119:533-41.

3. Shires T, Williams J, Brown F. Acute change in extracellular fluids associated with major surgical procedures. Ann Surg 1961;154:803-10.

4. Brandstrup B. Fluid therapy for the surgical patient. Best Pract Res Clin Anaesthesiol 2006;20:265-83.

5. Clark JR, McCluskey SA, Hall F, et al. Predictors of morbidity following free flap reconstruction for cancer of the head and neck. Head Neck 2007;29:1090-101

6. Myers LL, Sumer BD, Defatta RJ, Minhajuddin A. Free tissue transfer reconstruction of the head and neck at a Veterans Affairs hospital. Head Neck 2008;30:1007-11.

7. Konstantinides S, Geibel A, Heusel G, Heinrich F, Kasper W, Investigators MSaPoPE-T. Heparin plus alteplase compared with heparin alone in patients with submassive pulmonary embolism. N Engl J Med 2002;347:1143-50.

8. Gan TJ, Soppitt A, Maroof M, el-Moalem H, et al. Goal-directed intraoperative fluid administration reduces length of hospital stay after major surgery. Anesthesiology 2002;97:820-6.

9. Monnet X, Rienzo M, Osman D, et al. Passive leg raising predicts fluid responsiveness in the critically ill. Crit Care Med 2006;34:1402-7.

10. Funk DJ, Moretti EW, Gan TJ. Minimally invasive cardiac output monitoring in the perioperative setting. Anesth Analg 2009; 108:887-97

11. McKendry M, McGloin H, Saberi D, Caudwell L, Brady AR, Singer M. Randomised controlled trial assessing the impact of a nurse delivered, flow monitored protocol for optimisation of circulatory status after cardiac surgery. BMJ 2004;329:258.

12. Noblett SE, Snowden CP, Shenton BK, Horgan AF. Randomized clinical trial assessing the effect of Doppler-optimized fluid management on outcome after elective colorectal resection. Br J Surg 2006;93:1069-76.

13. Pearse R, Dawson D, Fawcett J, Rhodes A, Grounds RM, Bennett ED. Early goal-directed therapy after major surgery reduces complications and duration of hospital stay. A randomised, controlled trial [ISRCTN38797445]. Crit Care 2005;9:R687-R693

14. Sinclair S, James S, Singer M. Intraoperative intravascular volume optimisation and length of hospital stay after repair of proximal femoral fracture: randomised controlled trial. BMJ 1997;315:909-12.

15. Venn R, Steele A, Richardson P, Poloniecki J, Grounds M, Newman P. Randomized controlled trial to investigate influence of the fluid challenge on duration of hospital stay and perioperative morbidity in patients with hip fractures. Br J Anaesth 2002;88:65-71.

16. Wakeling HG, McFall MR, Jenkins CS, et al. Intraoperative oesophageal Doppler guided fluid management shortens postoperative hospital stay after major bowel surgery. Br J Anaesth 2005;95:634-42. 